\title{
El INCA GARCILASO DE LA VEGA EN EL MUNDO DE LAS IDENTIDADES
}

Oscar Paredes Pando ${ }^{1}$

\section{RESUMEN}

La niñez y parcialmente la juventud del Inca Garcilaso de la Vega, transcurrió entre nobles subordinados y aventureros de poder creciente; hijo del triunfante Capitán, y de la ñusta prima del Inca. Conforme crecía, su forzada españolización negaba el mundo de su madre. Toda una vida muy compleja, siempre acompañada de contrariedades. Fue testigo de la grandeza del Cuzco, a la vez, de su saqueo y destrucción; también conoció a los responsables de la muerte de su tío Atao Wallpa. Las deslealtades entre los castellanos, tal vez, le permitió

entender a los intrusos; era notorio el propósito de desindianizarlo, mucho más cuando aprendía a rezar, también el latín que le hacía soñar en ir a Salamanca. Seguramente conforme crecía, llegaban algunas preguntas, elementales de formular, pero muy complejas de responder: ¿quién soy? ¿Inca?, no, no, ¿mestizo? tal vez, tal vez, ¿español?, imposible, imposible. Entre afirmar y negar, siempre juntas, como entre el Capitán y la ñusta Isabel, aquel "ñuqanchis" y "ñuqayku" sería toda una ecuación cultural sin resolver, aunque nunca renunció heredad alguna. Los conflictos los llevaba a su interior de manera muy consciente, inclusive palpando las distancias de aquel "español" antes de su partida, a indígena, allá lejos. ¿Entonces, el pregonado mestizaje donde quedaba?

PALABRAS CLAVE: Inca Garcilaso de la Vega, identidades

\section{ABSTRACT}

The Chilhood and a part of the youthfulness of Inca Garcilaso de la Vega was among nobles subordinates and adventurers of increasing power. Captain triumphant's son, and Inka's cousin son called Nusta. With that forced hispanization he denied his mother's world. He has a complex a lifetime, always accompanied by setbacks. He witnessed the greatness of Cuzco, at the same time their looting and destruction. He also met the responsibles for the death of his uncle Atao Wallpa. The disloyalties among the Spaniards, perhaps, allowed him to understand the intruders. Also was notorious the purpose of "desindianizarlo", much more when he learned to pray, also the Latin language that made him dream to travel to Salamanca. Surely as he grew, came to him some questions, basic questions but very complex to answer: Who am I? Inka? No, no. Mestizo? Spanish? Impossible, impossible. Moments of affirmation and crisis;

both together, why deny them. Among the Captain and Nusta Isabel, that "ñuqanchis" and "ñuqayku" would be a cultural equation unresolved. Therefore never quit that inheritance: $\mathrm{He}$ kept the conflicts inside him in a very consciously way, tough, he was feeling distances around that "Spanish" identity before his departure, "indigenous" identity, far away. So, where was the proclaimed miscegenation?

KEYWORDS: Inca Garcilaso de la Vega, identities.

1 Doctor en Mundos Indígenas, do cente de la Escuela Profesional de Antropología de Facultad de Derecho y Ciencias Sociales de la Universidad Nacional de San Antonio Abad del Cusco. E-mail: oparedesp@yahoo.com 
$J^{u}$ untamente que catorce universidades del mundo, desde la Presidencia de la Comisión de Cultura de la Municipalidad del Cusco, el 2009, me correspondió conducir el Programa de Conmemoración del Cuatricentenario de la edición de los "Comentarios Reales" del Inca Garcilaso de la $\mathrm{Vega}^{2}$, evento que por su dimensión internacional fue registrado y apoyado por la UNESCO, entidad que a la vez tuvo la gentileza de otorgarme la medalla "Simón Bolívar", gesto que me compromete a estudiar y conocer mejor a quien sentó las bases de nuestro país.

De aquel Programa conmemorativo la alta especialización de los ponentes, me permitió entender la dimensión de la obra del Inka Garcilaso de la Vega, sin embargo, como antropólogo buscaba entender al hombre y persona que gestó aquel monumental legado, pues era evidente las complejidades sociales y culturales que tuvo que enfrentar a lo largo de su vida, gran parte de todo ello, se "reduce" en la cuestión de la identidad y lo identitario, aspecto inherente a la condición humana.

Tal vez, al contrastarnos con los demás, nos conocemos y comprendemos mejor, descubriendo nuestras particularidades; desde luego, como seres humanos, todos, somos iguales pero diversos.

El punto de partida, sería la naciente estructura política surgida a partir de 1529 , años antes de lo ocurrido en Caxa Marka, cuando se creó y adjudicó a Francisco Pizarro la Gobernación de Nueva Castilla en América del Sur. Estaba sancionada la decisión de los grandes cambios, siendo tan solo cuestión de tiempo, hasta que llegó noviembre de 1532 y Atao Wallpa fue muerto. Así, la historia, nos entregaba una peculiar partida de nacimiento cuya validez ya se prolonga más de quinientos años.

Una y otra vez tenemos que regresar a aquel tiempo y espacio, a manera de inicio para explicar muchos de nuestros problemas, además, los procesos sociales son un continuum con diversas velocidades, todo un reto para las ciencias sociales, como escribe Hugo Neira ${ }^{3}$ : "desde abajo estamos ingresando con nuevas capas emergentes a la globalización, donde la sociedad peruana se mueve más rápidamente que sus antropólogos".

Aquellos tiempos y espacios, se han convertido en referentes obligatorios, aparentemente con nuevos inicios, resultantes de ciertas condiciones históricas, con otros actores, caso de los aventureros castellanos y europeos en general, quienes, luego de degollar o ahorcar al Inca Atao Wallpa, tomaron la determinación de hacerse de la Gran ciudad del Cusco, mayor metrópoli del continente; ciudad que simbolizaba a aquella sociedad, cultura y

2 Dentro del Programa de Conmemoración de aquel Cuatricentenario, como Regidor-Presidente de la Comisión de Cultura de la Municipalidad Provincial del Cusco, promoví la re edición facsímil de "Historia General del Perú" (Segunda Parte de los Comentarios Reales), tomando como fuente también otra reimpresión facsímil de 1722.

3 Neira, Hugo. ¿Cómo pensar esa tumultuosa emergencia?, Lima, El Comercio, 29 de mayo de 2016. 
también al poder en todas sus expresiones, para el efecto los aventureros quisieron otorgarle otro comienzo con el acto de fundación, pretensión que lastimosamente selló el inicio del conflicto, aquello, ocurriría el 23 de marzo de 1534, atrevimiento que buscaba negar la fundación mítica de la Ciudad "Cabeza de los Reynos del Perú", luego levantada por Pachacuti (Betanzos, 1999).

Si bien somos parte de una Formación Social, el Cusco, es el Cusco, expresa todo un proceso social, tiene otro principio, menos difuso y sin perderse demasiado en la leyenda, su misma dinámica fue distorsionada a partir de la mayoría de los registros nacidos en el siglo XVI, distorsiones que nos exige un replanteamiento, como una re lectura de todo lo ocurrido.

Los castellanos ya en el Cusco, "dueños de solares e indios", se paseaban sobre sus caballos, habiendo convertido la ciudad sagrada en un centro de operaciones: Transcurría el tiempo, iban y regresaban, entre triunfos y derrotas, uno de ellos fue el Capitán Sebastián Garcilaso de la Vega, quien, en una oportunidad, constató en las proximidades del Qorikancha, ya bautizado como Santo Domingo, a un grupo de indios nobles ataviados con decoro y hasta con lujo, ellos, tal vez buscaban cierta protección. El Capitán vio que sobresalía un rostro juvenil en aquel grupo compacto, se trataba de la ñusta Isabel Chimpu Oqllo, nada menos que prima de los incas Atao Wallpa y Waskar; la jovencita empezó a inquietar al aventurero, quien luego frecuentaría al hogar de la india noble, la hizo madre, así, nació el 12 de abril de 1539, el niño Gómez Suárez de Figueroa; pasaron los años, abandonó aquel nombre para firmar y hacerse conocer por siempre como Garcilaso Inca de la Vega. Aquella determinación, no fue simple cambio de nombre, fue un acto que se enmarca en las complejidades de la identidad. ¿Cómo surgió y de desenvolvió en aquel hombre?, en las siguientes líneas ensayaremos algunas respuestas.

\section{El nuevo escenario e imaginados diálogos}

Quienes llegaron de aquella península europea, luego de haber pisoteado los Mandamientos de Moisés, participaron como católicos en el acto central de aquel protocolo, nos referimos a la celebración de la misa o eucaristía, ritual conducido por Vicente Valverde, el mismo de la acción traidora para la celada en Cajamarca al Inca Atao Wallpa.

Dicho ritual dejaría absorto a los cusqueños, sobre todo cuando el religioso invocaba engullirse el "Cuerpo y sangre de Cristo", su Dios, así, del conflicto estrictamente bélico, se pasaba al conflicto más complejo, el ideológico ${ }^{4}$.

El pedido de Valverde de hacerse del Qoricancha, precipitó la decisión de repartirse la ciudad en solares, expropiación que comprendió a sus habitantes.

Los invasores se fueron posesionando y afincando sus ideas, la misma territorialidad tomaba otro perfil como rasgo fundamental de lo identitario. Luego de milenios de adecuado funcionamiento, empezaba a desestructurarse, el allin kawsay empezaba a desmoronarse, la crisis se generalizaba llegando hasta nuestros tiempos. El Sapan Inca, desde el Valle del Watanay, había logrado otorgar un genuino perfil a la institución más compleja de la política, logrando un Estado previsor y distributivo, distinto a aquel de Occidente, soporte de los procesos de acumulación y desigualdades.

La naciente estructura de dominación, fue gestando nuevas jerarquías, con ventajas para el aventurero, que además se mostraba como el "salvador" frente a

4 Ideología, término formulado por Destutt de Tracy (1796), también ingresaría como matriz analítica hasta nuestros días, aunque el contenido epistemológico otorgado, lo hiciera más complejo. 
la situación de crisis promovida por ellos, quienes culpaban de todo al conflicto entre Atao Wallpa-Waskar, soberanos, tíos legítimos de Garcilaso Inca de la Vega.

Sobre aquella inquietud que generó la joven ñusta Isabel Chimpu Oqllo, al Capitán Sebastián Garcilaso Inca de la Vega, Luis Alberto Sánchez (1979), imagina que en aquellas circunstancias habrían de darse pequeños diálogos: ¿Quieres ser bautizada?, si taytay, te llamarás Isabel, si Taytay. Fue, ¿afecto o relación subalterna?,

“...en mis niñeces me contaban sus historias, como cuentan las fábulas a los niños. Después, en edad más crecida me dieron larga noticia de sus leyes y gobiernos..."

lo cierto es que nació el niño Gómez Suárez de Figueroa, mientras tanto, continuaba la destrucción de la ciudad. Que dichosos fueron Martín de Moguer, Martín Bueno y el escribano, comisionados del Gobernador, primeros en llegar al Gran Qosqo en 1533, fueron los únicos en conocer la grandeza de la ciudad, pero también los primeros en saquearla, en desmontar el Qorikancha.

La sociedad andina empezaba a desestructurarse social y culturalmente, había empezado el despoblamiento, la dispersión, la matanza iniciada en Caxa Marka, eran ya notorios los efectos de la compulsión biótica.
En la frontera norte del Tawantinsuyo, ya habían nacido los primeros "hijos naturales", fue en el valle de Tangarará, a orillas del río Chira, donde fundaron a mediados de julio de 1532, la primera ciudad española. En el pueblo pesquero de Colán, levantaron su primera iglesia. Aquellos "hijos naturales de los conquistadores", no tenían relación con nobleza alguna, tal vez, con algunas elites locales nada más. No fue el caso del niño Gómez Suárez de Figueroa, también "hijo natural", pero de madre noble y cusqueña. Emergía una nueva generación, nacían niños "hijos de españoles que ha habido en indias, los cuales andan perdidos entre los indios [...], se recojan y en Mesoamérica...", de ahí que en 1533, fuera sancionada la Real Cédula, que disponía:

\section{"El Rey [...] Yo he sido informado que} en toda esa tierra hay mucha cantidad de alberguen todos en esa ciudad en los otros pueblos [...] y a los que no tuvieran padres hagáis poner en oficio [...]" (R. Conetzke, 1953: 671)

Fue el niño Gómez Suárez de Figueroa, el primero, por lo menos en el Cusco, hasta donde se tiene registrado, en ser reconocido por su padre el Capitán Sebastián Garcilaso de la Vega, y sobre todo, en recibir un nombre vinculado dentro de la ascendencia paterna a humanistas como el poeta toledano, Gómez Suárez de Figueroa.

Aquel niño sería el primer hijo de la ñusta Chimpu Occllo, más no del Capitán, que según el documento hallado por Rafael Aguilar y dado a conocer por Aurelio Miró Quesada Sosa, aquel aventurero, tuvo otro bastardo en su criada Beatriz de la Vega, llamado Diego de Vargas, quien oficiaba de modesto sacristán de una capilla.

En el hogar de la ñusta, el niño Gómez Suárez aprendía y hablaba con fluidez el 
quechua " "mamitay, taytay t'anta, ukucha", sería parte de su habla cotidiana, mientras que para el Capitán, de trataba de madre, padre, pan, o ratón. Así empezaría el asunto identitario con todas las complejidades que le acompañaron toda su vida. El mismo recuerda sobre su educación, o más propiamente sobre su españolización, tarea encargada de manera particular a Juan de Alcobaza; dice el hijo del Capitán, que compartía su instrucción con los hijos de los hermanos Pizarro, posiblemente también en indias nobles, niños, que tuvieron otra suerte ingresando al mundo del anonimato. Lastimosamente no se cuenta con investigaciones en la línea desarrollada por mi profesor Juan Marchena Fernández (1992), cuyos resultados son fundamentales para entender la estructuración de la nueva sociedad surgida a partir del siglo XVI. Se sabe que el mismo Francisco Pizarro, en Caxa Marka al recibir de Atao Wallpa a Inés Huaylas Yupanqui, como compañera, la noble india le dio al Gobernador, dos hijos (Raquel Chang-Rodríguez, 1996)

Fray Vicente Valverde, primer Obispo del Cusco, entendió que la educación de aquellos niños era fundamental para su tarea evangelizadora, de ahí que en 1535 había logrado de la corona la autorización para fundar la Escuela parroquial, y en donde el Canónigo Juan de Cuellar se encargaba de formarles en gramática y latín, deseando hacer de todos ellos futuros estudiantes de Salamanca, y así contar con clérigos y teólogos que se sumaran a la iglesia en su labor misional.

Antes de las tareas de Juan de Alcobaza y de Juan de Cuellar, aquel "hijo del conquistador", en el hogar materno, empezaba su desarrollo cognoscitivo con el runasimi de su tío abuelo Cusi Huallpa y los capitanes Juan Pechucta y Chauca Rimachi, responsables de relatarle sobre el pasado glorioso de los incas, asunto confirmado cuando el Inca escribe: "En este tiempo tuve noticias de todo lo que vamos escribiendo porque en mis niñeces me contaban sus historias, como cuentan las fábulas a los niños. Después, en edad más crecida me dieron larga noticia de sus leyes y gobiernos..."

Eventualmente también aquellos niños con sus padres castellanos aprenderían algo de su idioma. En el caso de Gómez Suárez de Figueroa, hijo de Capitán, entre uno y otro espacio sociocultural alimentaría cierto egocentrismo, pues, entre la madre india de nobleza y el soldado triunfante, la atención y preocupación por el niño, sería algo particular, desde sus familias, aquello que buscaba, siempre lograría, pues, estaba al centro, situación que no compartían todos los niños, aun siendo "hijos de conquistadores".

Como escriben, en la "anchurosa" casa paterna, solar que hasta 1542 había pertenecido a Pedro de Oñate, Isabel Chimpu Occllo, atendía a los amigos del Capitán, oportunidades cuando el niño, sería asistido por su padre, conociendo además a casi todos los responsables de la muerte de Atao Wallpa, primo de su madre; también dentro de su primera juventud fue testigo de deslealtades entre los castellanos, sobre todo, en las guerras civiles, de los que dirá más tarde en sus escritos: "a quién yo conocí"; contrariamente a otras apreciaciones, sobre Francisco Pizarro, dice que fue "cariñoso, fiel a su palabra y hombre de gran verdad".

También en el solar de Cusipata, el niño Gómez Suárez, pasó días de hambre y angustia mortal junto a su madre, cuando los conflictos se daban entre los aventureros, por cuanto la casa solariega fue cañoneada, por aquellos camaradas de su padre.

Cuando aprendía latín, toda su aspiración se hallaba puesta en ir alguna

5 Fue tanta la capacidad de resistencia del mundo andino al propósito evangelizador de occidente, que en 1538, el III Concilio Limense, dispuso el aprendizaje obligatorio de la lengua general (quechua o aymara) por parte de los curas; asimismo la enseñanza obligatoria del castellano y el latín en los Colegios Reales. 
vez a la Universidad de Salamanca, en aquellas circunstancias, el joven se sentiría más ligado a la sociedad y cultura de su padre, una especie de castellano emergido entre los indios, participando de algunas fiestas occidentales, caso de la celebración del bautismo del Príncipe Sayri Túpac, un noble familiar directo suyo.

En todas aquellas prácticas del que participaba el joven Gómez Suárez no había como se supone intercambios culturales, muchos menos "diálogos", eran evidentes las imposiciones, además fueron tiempos cuando familiares de su madre, desde Vilcabamba continuaban con la resistencia anticolonial, desde luego, sin propósitos de forjar discursos identitarios, pero si evidenciaban reafirmaciones de corte político, pues, los "Incas de Vilcabamba" expresaban autodefiniciones al interior del Estado Inca, que luchaba por subsistir. Garcilaso escribe: “....estas y otras semejantes pláticas tenían los Incas y Pallas en sus visitas, y con la memoria del bien perdido siempre acababan su conversación en lágrimas y llanto, diciendo: "Trocósenos el reinar en vasallaje... En estas pláticas, yo como muchacho, entraba y salía muchas veces donde ellos estaban y me holgaba de las oír, como holgaban los tales de oír fábulas" (Comentarios reales, I, 1, 15).

Las reconciliaciones simplemente no pertenecían a aquellos tiempos, la metrópoli madrileña se puso de espaldas a la insinuación de Bartolomé de las Casas, sobre un posible reconocimiento a la autodeterminación de los vilcabambinos, que entonces expresaría una peculiar estructura política de excepcional calificación jurídica, donde los indígenas al volver a ser gestores de su destino, dejaban de lado ser considerados objetos pasivos, tal cual buscaba el Estado colonialista, estaba sentando sus bases con las tareas evangelizadoras y la imposición ideológica, acciones que tenían como mira la "desindianización", empezando con los "hijos de los conquistadores", situación que también debió enfrentar Gómez Suárez y su generación, renunciando a su herencia cultural. Desde luego, él no lo hizo muy a pesar que aquel panorama caracterizado por la oposición "católicos y civilizados", frente a los "indios paganos" que cada vez radicalizaría el conflicto cultural.

Aquí tiene lugar lo señalado por Vázquez Medel (1998:5), que cada ser humano pertenece a un tiempo, a un decurso temporal. A su vez, esos espacios y tiempos le pertenecen. "Se trata de una doble y recíproca per-tenencia: una tenencia hasta el final perfectiva". Todo ello sería el modelamiento identitario, con la adecuación o acomodo a las nuevas condiciones históricas y en la perspectiva de garantizar su existencia, como que es constatable la cultura andina de estos tiempos, presentada forzadamente a través del discurso del mestizaje que busca explicar los procesos de cambio cultural a manera de tendencias mutuamente asimilables, más no explica, o lo hace rara vez, para decir cuál es la diferenciación cultural, tal perspectiva sería una negación al mismo discurso.

\section{Entre crisis y afirmación identitaria}

Obviamente, el Capitán Garcilaso, mostraba interés por situar a su hijo en el seno de la tradición castellana, mientras tanto en el seno de la familia indígena de la madre acrecentaría su prestigio y jerarquía frente a "los otros", los indios aún de su generación, no necesariamente hijos de una ñusta de la nobleza.

Aquella pretensión del padre, en el fondo ahondaba la situación conflictiva de Gómez Suárez de Figueroa. Su madre de una sociedad acosada, sojuzgada pero de trayectoria gloriosa y digna, el padre, activista de la aventura y conquista, quien cada vez desde el Cusco tomaba distancia de los demás, así, los indios fueron quedando en sus pueblos, mientras que la ciudad cambiada de perfil urbano. El Cusco con solares, resultado de la distribución o "repartija"; otra de las consecuencias, fueron 
las distancias sociales, los indios cada vez desprovistos de sus derechos, pero con más obligaciones.

Se dice, manteniendo las jerarquías políticas, económicas y raciales, mientras los naturales tributaran y sirviesen en la encomienda y en la mita, les era permitido vivir de manera relativamente autónoma, conservando algunas de sus instituciones sociales a condición de sujetarse a la fe cristiana. Esta situación se daría probablemente al concluir la resistencia en Vilcabamba, por lo que no fue conocida por Gómez Suárez de Figueroa, debido a su temprana ausencia, pero muybien informado a pesar de la distancia,

Obviamente fue en la morada de la madre india y noble, y la del padre castellano y dominante, que empezaría la natural inquietud por su identificación e identidad: ¿Quién soy?, ¿inka?, no, no ¿mestizo? tal vez, tal vez, ¿español?, imposible, imposible. Preguntas que empezaba a rondar su privilegiado cerebro.

Sin duda, debía establecer diferencias para definirse. Tal vez, también buscaría contrastarse "con sus iguales", quienes siendo hijos de los aventureros en indias nobles, no merecían atención alguna de sus padres, como que sí él fue recibiendo. La estructura naciente sería muy compleja, otros niños, hijos de soldados sin jerarquía especial pero entre los mismos conquistadores y en "indias comunes", o hijos de padres desconocidos, de padres muertos en batallas, en fin todo un enmarañado social, sobre todo por la línea paterna.

Bajo aquellas condiciones, a momentos Gómez Suárez de Figueroa, habría de identificarse con su sentimiento de Sí, cerca al mundo de su madre. Y a momentos con la imagen del "otro", o sea, su padre el Capitán, soldado triunfante, pero en circunstancias perseguido, que llegó a ser Corregidor y Justicia Mayor del Cusco, de quien aquel "hijo natural" fue su "escribiente de cartas".

La escuela parroquial habría de ser la institución donde se fue avizorando o representando la composición de la sociedad, seguramente en su mayoría quechua hablantes, cuyos padres pertenecían a la esfera dominante. Mientras tanto, otros niños, también indios de padres desconocidos, sin posibilidad de acceder a la escuela, pero seguramente obligados a aprender las oraciones y cánticos en castellano, formas efectivas para la evangelización; desde luego el mundo lúdico debía encubrir toda aquella complejidad social en que fue creciendo el futuro autor de los Comentarios Reales.

Merece recordar que sólo en 1550 (Valladolid, 7 de junio), fue aprobada la Real Cédula "Sobre el Enseñar a los Indios el idioma Castellano":

"El Rey [...], dar orden en su instrucción y conversión a nuestra santa fe católica [...], uno de los medios principales que ha parecido que se debería tomar para conseguir esta obra y hacer en ella el fruto que deseamos, es procurar que esas gentes sean ensañados en nuestra lengua castellana [...]" (México 1968. Libro 4, fol. 239v)

Tal vez la primera adversidad de Gómez Suárez, fue, cuando su padre rechaza a su madre Isabel como esposa, la prefiere como concubina. Recuérdese que para atenuar ciertos conflictos en Mesoamérica y el Caribe, bastante temprano, se conoció la Real Cédula "Sobre Casamientos de Españoles con Indios":

"Toledo, 19 de marzo de 1525. El Rey. Reverendo in Cristo, padre obispo de la iglesia de Santa María de Antigua de Darién que es en tierra firme llamada Castilla de Oro [...], sería muy servido y vendría mucho provecho y paz a la dicha tierra y sosiego [...] yo vos mando y encargo mucho que cada y cuando algunos de los dichos 
españoles quisieran casarse ellos o sus hijos e hijas con los dichos indios y los dichos indios con los dichos españoles, les ayudéis y favorezcais en todo [...] (México 1968. Libro 4, fol. 239v)

Es posible que aquella Real Cédula se haya ampliado para todos sus dominios, de ahí aquel matrimonio de la princesa incaica doña Beatriz Clara y Martín García de Loyola, no tendría inconveniente alguno, por lo demás, de trataba de una "boda entre nobles". Según la Dra. Rostworoski (1989:153), "con este matrimonio emparentaron entre sí y con la Real casa de los Reyes Yngas del Perú las dos casas de Loyola y Borja...", obviamente, entre otros efectos fue seguir segmentando aquella sociedad.

La nobleza de Isabel Chimpu Occllo, estaba fuera de toda duda, y aquellos argumentos para justificar la resistencia del Capitán a contraer matrimonio con Isabel, difundidos como que "habían órdenes y así conservar sus posesiones de las encomiendas", es inconsistente. El Capitán contrajo matrimonio con Luisa Martel de los Ríos, abandonando a la princesa inca, pero ahí no quedó la determinación del castellano, sino que le impuso como marido a Juan de Pedroche, otro español, pero de "baja condición", la ñusta le dio dos hijas: Luisa de Herrera y Ana Ruiz.

Aquella circunstancia realmente sería muy dura para Gómez Suárez, quien debió mirarse en el espejo, además de verse, preguntarse: ¿quién era realmente?

Identificación, identidad e individualidad ingresaban para siempre en el mundo del hijo del conquistador. No es que sociedades y culturas se integraran mecánicamente para un supuesto "mestizaje armonioso". El mestizaje, desde un inicio, ha sido y es un discurso ideológico, muy eficaz por cierto para cubrir perfectamente diversos conflictos, aparenta una relación horizontal, donde los "préstamos culturales" —como difunde la teoría antropológica conservadora, nacida también de acciones colonialistas - concurran de ambas vertientes, que a la vez se constituyen en partes de un todo. En estos tiempos el mestizaje encuentra su proyección en el discurso de la interculturalidad, desde luego remozado, pues, nació de la necesidad de encontrar propuestas políticas a las grandes diferencias culturales existentes en el mundo, pero que debiera pasar necesariamente por las mediaciones políticas, económicas e históricas.

Dado el notorio énfasis de la interculturalidad, a partir de 1990, su propósito evidentemente es el "universalismo" inclusive monocultural propia de la globalización, también, respondiendo a cierta 'ola culturalista' promovido por la misma Naciones Unidas, apoyándose para el efecto en algunos resquicios del Convenio 169 de la OIT, así, el debate, etnìa o clase social, surgido aún en las Declaraciones de Barbados, poco a poco será dejado de lado.

Aquel mestizaje que buscó situarse en las Ciencias Sociales a nombre de una "armónica relación" no pudo encubrir a lo largo de cientos de años, su propósito de negar la capacidad de la cultura andina a la resistencia y así conservar su existencia. Expresiones como "sincretismo", y otras, han sido el soporte de las supuestas "relaciones" entre culturas. El tiempo ha demostrado que tales relaciones son desiguales, finalmente constituyen la base de las estructuras de dominación de una de las partes.

Mientras tanto, el enfoque multiculturalista, al buscar la reafirmación de la diversidad cultural, reconoce la capacidad de las sociedades de gestar sus diferencias e identidades, fundamento inclusive en estos tiempos para desarrollo humano.

Estos abordajes son necesarios para las nuevas lecturas e inclusive para un replanteamiento de la cuestión de las identificaciones e identidades, evitando así 
todo subjetivismo. Hoy, no debemos seguir empantanándonos en estos temas mediante dudosas categorías, como lo es la "aculturación", que supone procesos simples en la relación de dos o más culturas, donde determinados elementos culturas fluyen sin dificultad alguna en uno u otro sentido; así, el resultado, sería también las mutuas adaptaciones, lo que no es así, por cuanto, lo que existe es un flujo hegemónico en uno $\mathrm{u}$ otro sentido, y que al final se forja una estructura jerárquica, donde la cultura subordinada ingresa en un proceso de pérdida de muchos de sus elementos.

En casos extremos aquella "aculturación" deriva en etnocidio, es lo que sucedió con $1 / 5$ de los pueblos de nuestro continente, que han dejado de hablar su lengua indígena o "aborigen", o con los 44 pueblos indígenas que utilizan como única lengua el castellano. Desde luego, efecto no generalizable, pues, depende de la capacidad de respuesta o resistencia de determinadas sociedades, de ahí que luego de 500 años de presencia de occidente, hoy, la base socio-cultural indígena de Centro y Sud América, está representado por 420 lenguas indígenas en uso, donde además 5 Naciones ètnicas superan el millón de habitantes: Quechua, Nahualt, Aimara, Maya y Kiché.

Si nuestro país, es hoy, una sociedad pluri y multicultural, muy a pesar del etnocidio y del genocidio de los quinientos años transcurridos, es debido a la capacidad de resistencia de nuestras culturas, muchas de cuyas prácticas aparentan un sometimiento a lo ajeno, pero que en el fondo, son un modo de garantizar su existencia.

Gómez Suárez de Figueroa y su generación fueron gradualmente unos más que otros en la búsqueda del "quien soy", para así forjar una "conciencia del yo". Obviamente en el caso de nuestro personaje, nacido en el Cusco, centro del mundo andino, aquel niño fue creciendo, atestiguando, y recibiendo la gran herencia de una sociedad muybien organizada.

Con los hechos ya conocidos y ocurridos durante el siglo XVI, todo empezó a desgajarse, naciendo las preocupaciones de:

—¿Quiénes somos?

—¿Quiénes son los otros"?

—¿Quiénes de los otros nos reconocen?

Tal vez, estas ecuaciones culturales podrían ser resueltas por conceptos andinos como el "ñuqanchis" y el "ñuqayku", que son mucho más que simples conjugaciones gramaticales.

En aquel complejo mundo de Gómez Suárez de Figueroa y los "otros" "no reconocidos" pero con algunos nuevos privilegios, sí o sí, participarían de los pronominales yo-tu-él-nosotros.

¿Lograba Gómez Suárez de Figueroa aproximar las categorías "yoidad" y "otredad" entre aquel mundo de su madre Chimpu Occllo y la del Capitán?

Para el Capitán, ni Isabel, ni el niño Gómez Suárez, serían su familia, pues, muy poco aportarían para reverdecer el blasón de los Lasso de la Vega y Gómez Suárez. Isabel, muy a pesar de su abolengo, generaba entre los curas la pregunta, ¿tiene alma?

Desde luego, el Capitán había logrado un entorno de seguridad con la familia de la noble Isabel.

Ser, identidad y diferencia, unidad y diversidad son determinaciones plurales en estrecha relación estructural y que seguramente acompañaron toda su vida al Inca Garcilaso de la Vega.

El Capitán, falleció en 1559, sus bienes pasaron a poder de las "hijas legítimas" quienes dejaron de existir muy jóvenes. Fue entonces que el Estado colonial se encargó 
de administrar los bienes del extinto Capitán y Corregidor, aunque antes de morir había heredado la cantidad de cuatro mil pesos para su hijo Gómez Suárez de Figueroa, a fin de financiar sus estudios en España; también en su disposición testamentaria, le heredó una chacra de coca en Havisca-Qosñipata, parcelas y cultivos del Inca Huayna Capac, todas ubicadas en la región de la Alta Amazonia de

Paucartambo, que también le pertenecerían por ser descendiente del Inca.

Gómez Suárez, no renunció a ninguna heredad, de manera muy consciente y con los conflictos llevados interiormente, se posesionará de ellas, seguro de su mundo cultural y de su lugar en la sociedad, escribiría en sus Comentarios Reales:

"[...], a los hijos de español y de india, o de indio o de española nos llamaban mestizos por decir que somos mezclados de ambas naciones: fue impuesto por los primeros españoles que tuvieron hijos en Indias y por ser nombre impuesto por nuestros padres, y por su significado me lo llamo yo a boca llena y me honro con él..."

Toda una reafirmación identitaria, describiéndose, resaltando su condición, tal vez, presentado de diversas maneras, lo elegirá resaltar una sobre otras, sin que ello suponga en ninguna circunstancia negar a las demás.

Debo indica que antaño la conceptualización de identidad cultural fue una pluralidad en la unidad, en estos tiempos, se va hacia la conceptualización de la igualdad en la diversidad. En palabras de José L. Borges, es aquella "cosa rara que somos", no sólo la existencia de presunciones fundamentales compartidas, como el yo en la muchedumbre, también ciertas ambigüedades.

El profesor Lisón Tolosona (1997:63) reitera que ninguno de estos estados-limite, puede estar fuera de la cultura, por cuanto, en circunstancias aparece como ordenador en aquellas culturas que perciben su cosmos de manera diferente. Dentro de todo ello, como ya indicamos, el mismo espacio social, no es neutro, pues, a su interior se definen los procesos de identidad.

\section{El manto protector del viaje sin retorno}

Ha llegado la hora, Gómez Suárez de Figueroa, decide ausentarse del Cusco, en enero de 1569 , y a los veintiún años se aleja de toda su familia, su destino es la península Ibérica, España le ofrecería algo nuevo. Polo de Ondegardo, se entera de aquella determinación, lo busca y en un ambiente semioscuro, le muestra unos bultos. Brilla en la penumbra una diadema de oro sobre la frente de una de las momias. ¡Tus antepasados los inkas! ¡Wayna Qapaq, tu abuelo! Tupaq Yupanki..., Pachacuteq, Wiraqocha...Uno, y otro y otro. El joven, sin reacción. Otro momento de orgullo inconmensurable, pero también de crisis identitaria.

Definitivamente se va. ¿Acaso el propósito de acceder a los títulos de Gómez Suarez de Figueroa, fueron las cubiertas de aquella crisis de identidad?

Si bien el objetivo inicial del viaje fue ir a la Corte, a solicitar las mercedes que consideraba le correspondían a su padre por los servicios prestados, por otra, buscar la restitución patrimonial de su madre. El tío paterno, le había advertido: "debes ir a la Corte bien apadrinado y con algunos bienes..."

El Consejo de Indias desestimó sus pedidos, situación muy difícil, por un momento pensó en retornar al Cusco, inclusive y para el efecto contaba con la Real Cédula (27.06.1563), finalmente desistió, optando por el enraizamiento en aquellos lares, alejándose por siempre de su patria. También resolvió cambiarse de nombre, aquel Gómez Suárez de Figueroa, llegado del Perú, aparece una vez y con una partida bautismal como 
“Gómez Suárez de la Vega", luego, según Miró Quesada (1959: XII) desde el 22 de noviembre de 1563, con el orgulloso nombre heredado del Padre y de su deudo el poeta toledano "Garcilaso de la Vega".

La muerte de su madre la Palla incaica Isabel Chimpu Occllo a fines de 1571, fue para Garcilaso la desaparición del vínculo más hondo que lo unía al Cusco. Toma sus decisiones, posiblemente define sus proyectos, consciente que en España, aquella imagen de indio aún noble, tendría muchos límites; mientras tanto, con la imagen de "el Otro", hijo del conquistador, un Capitán, Corregidor y Justicia Mayor del Cusco, los límites serían menores.

No identificarse, sería vivir en delirio y angustia, que a momentos tuvo que enfrentar. Quizá a momentos a un paso de la locura.

Con la presencia eventual de Feliciano Rodríguez de Villafuerte, residente en Salamanca, condiscípulo suyo en la escuela parroquial del Cusco, llegaban los recuerdos: ¿os acordáis señor? En aquellas circunstancias la identificación tiene como efecto el sentimiento - inconsciente o consciente - de estar arraigado a algo, de estar para alguien, para la mamitay, no para la mamá Isabel.

Se alista en el ejército español, hasta que Felipe II le concede sendos despachos, el Inca busca posicionarse en una realidad ajena a la suya, donde la negación a las mercedes que le correspondían, a su padre el Capitán, desembocó en una gran desilusión.

Fueron aquellas nuevas circunstancias que le permitieron palpar las distancias que le separaban de "los demás", momentos en que se haría presente la reminiscencia de antaño y que estaba muy lejos. Sería el momento de búsqueda con "su otro", en tal circunstancia y embargado de nostalgia, ¿dónde refugiarse?, ¿en el Cusco?, estaba muy lejos, otra vez la crisis identitaria de la persona cuya infancia tuvo la aureola de la grandeza incaica de su madre, y a momentos de su padre, sobre todo cuando fue primera autoridad del Cusco.

De "aquel español" en el Perú antes de su partida, con mucho coraje, ingresaría una y otra vez, tal indígena en España. Así fue en 1590, cuando publica "La traduziòn del Indio de los tres Diàlogos de Amor de Leòn Hebreo, hecha de Italiano en Español por

¿Dónde refugiarse?, ¿en el
Cusco?, estaba muy lejos,
otra vez la crisis identitaria
... cuya infancia tuvo la
aureola de la grandeza
incaica de su madre, y a
momentos de su padre, ...
cuando fue primera
autoridad del Cusco.”

Garcilaso Inga de la Vega, natural de la gran Ciudad del Cuzco, cabeza de los Reynos y provincias del Pirù”

Aquí, no habla "a boca llena aquel mezclado que se honra", resurge lo indio de pasado glorioso, capaz de dominar otras lenguas y hacer traducciones.

\section{¿Entonces, aquel pregonado mestizaje donde quedaba?}

"La traduziòn del Indio...por Garcilaso Inga de la Vega...", no fue un simple y expresivo título, retrataba tiempos y espacios 
sociales suyos, además la doble per-tenecia. Tremenda reafirmación identitaria cultural, reduciendo sin desplazar por completo su identificación social conseguida en aquellos lares. En la primera dedicatoria a Felipe II, de su traducción (1586), figura por primera vez el apelativo "Inga", escribe además con firmeza: "para el deleite de indios y españoles, porque de ambas naciones tengo prendas".

Estaba en Montilla, mostrándose en su totalidad y límites, tras todo lo visible, a manera de cuerpo social y cultural supo simbolizarlo. Garcilaso Inga, fue constatando las fronteras culturales y sociales como ámbitos de separación y que podrían ser enfrentados, había que evitar, ¿cómo? Una de las maneras sería hacerse soldado al servicio de su majestad, más tarde escribir y corregir las versiones dadas por "los otros" de su sociedad y que él conocía mejor que "aquellos", finalmente, a los 60 años, viste el hábito haciéndose sacerdote, ¿otro refugio?

Garcilaso Inga de la Vega, aborda de manera directa lo indio-hispano, queda atrás Gómez Suárez de Figueroa. Aquella personalidad, fue secuencializada de una manera muy amplia, todos enmarcados en los mismos paradigmas historiográficos, en algunos casos tocando algo del Renacimiento, continuados en la Ilustración y prolongados con enfoques aún etnográficos de los siglos XIX y XX; inclusive dentro de los campos de la semiótica y la antropología cultural. Sobre el particular, Arnold Toynbee (1966: 93), puede auxiliarnos:

"En el rol de vínculo entre dos culturas dramáticamente diferentes, Garcilaso es un documento en sí mismo: uno de esos documentos humanos que pueden ser más iluminantes que cualquier registro inanimado, sea que éste tenga la forma de hileras de nudos amarrados a lo largo de cuerdas, o de hileras de letras trazadas sobre papeles"
Significa la construcción de identidad o identidades individuales y colectivas, sobre todo dentro de una nueva fisonomía de la misma ciudad, e inclusive de nuevas jurisdicciones de expansión y también de apropiación territorial. Dadas las nuevas condiciones del s. XVI, aquella emergente frontera cultural, a momentos, daba la impresión de estar ante un espacio de actuación compartida. Su esencia, fue el carácter cotidiano de dicha relación, del todo desigual y heterogéneo. Todo ello, no deja de ser una construcción simbólica, intangible, marcada por el complejo proceso de cambios, continuidad y hasta confrontaciones a partir del establecimiento del núcleo identitario representado por el Cusco.

Desde 1534, se fue ingresando a un nuevo inicio del proceso de construcción o reconstrucción de la identidad local, o en todo caso, del replanteo identitario acorde a las "innovadoras" condiciones históricas, sociales y también culturales, lo que no suponía necesariamente un terreno de armonía, pues las relaciones sociales eran asimétricas, era evidente la resistencia por una parte, por otra se persistía en la dominación.

¿Resistencia y dominación, fueron acaso el lei motiv de los tiempos coloniales?

El otrora Tawantinsuyo, sometido a procesos de cambios drásticos, inclusive de desterritorialización y re-territorialización, sería un nuevo escenario de reproducción cultural incluida la étnica, y embrionariamente lo nacional. Fue con las decisiones verticales del virrey Toledo, que habría de surgir un constructo deforme, no por ello dejaron de forjarse nuevas identidades, en parte, por las acciones generadas en el mismo Estado Colonial.

Como indicamos a Gómez Suárez de Figueroa, no le es posible volver al Perú -inclusive contaba con la autorización obtenida en Sevilla-, por cuanto la represión toledana contra todos los miembros de la 
realeza incaica, también le llegaría al hijo del Capitán Garcilaso, quienes no se fueron antes de su tierra, habían sido deportados y para siempre.

Que duro es suponer que las fronteras culturales y sociales constatadas por Gómez Suárez, hicieran de él a momentos y en España, una persona "sin patria sin progenitores".

Todo el tiempo en Montilla, salvo breves viajes a Córdoba, Badajoz, Sevilla y otros lugares; largos años muy bien aprovechados por el Inca mediante lecturas intensivas, aprendiendo además el italiano. Es suficiente constatar el inventario de sus bienes que fue levantado una semana después de su muerte, en su biblioteca habían diversos textos: Plutarco, Séneca, Horacio, Julio César, Maquiavelo, Boyardo, Ariosto, entre otros, que le dieron un gran soporte cultural a partir de los cuales podía emprender actividades diversas. Estaba presto para su tarea de ínclito escritor.

El tiempo, sus actividades, las mismas frustraciones, hicieron que su "yo" se redefiniera, buscando también situarse en términos de un "id" colectivo, pues, también había logrado forjar sus redes sociales. El Inca podía diferenciar "eso", "esto" o "algo que uno es". A pesar de las adversidades, no pregonaría "soy lo que soy". No podía escapar a identificarse en términos de per-tenencias. Su intento de asumir y conciliar sus dos herencias culturales, fue un reto que asumió con firmeza y orgullo, aunque aquellas herencias continuaban sumamente diferenciadas y jerarquizadas, una dominante, otra dominada pero con existencia garantizada a través de la estrategia del acomodo que podría significar hasta cierto punto subordinación, desde luego temporal, sin interesar cuanto tiempo.

Con la muerte de su madre Isabel Chimpu Occllo, el Inca deja las armas, y decide dedicarse a una labor humanística.
Inicia así su nueva vocación y destino al tomar el prototipo del caballero renacentista. Ya iba quedando zanjada hasta su muerte su identificación, persistiría tal vez el debate en su yo, no por ello "los otros" serían una manera de "complemento", con ellos, transcurría lo cotidiano de su vida, de modo que no serían colocados fuera del campo de su subjetividad, de ahí que en 1603 le enviaron desde el Cusco, una Carta Poder - eran tiempos cuando preparaba la publicación de su libro "Historia de la Florida y jornada que a ella hizo el gobernador Hernando de Soto"-, a fin que pudiera interceder por ellos, tal cual puede leerse en el siguiente texto:

Cusco, 20 de marzo de 1603

Poder: Juan Cota Yupanqui y Juan Amao

Chima, nietos y descendientes de

Manco Capac Inga; Alonso Puzconm de

Sinchi Roca; Felipe Titu Yupanqui;

Francisco Guaretito, de Mayta Capac;

Diego Rimachi Mayta, de Capac

Yupanqui; Benito Topa Yupanqui, de Inca

Roca; Pedro Benito Atao Yupanqui, de Yahuaruaca; Francisco Chalco Yupanqui y Luis Chaco Yupanqui, de Viracocha; Francisco Concha Tito, de Pachacuti; Francisco Pilcotopa, de Topa Inga Yupanqui; Alonso Total Atao y Diego Cusi Rimachi, de Guaynacapac; por ellos y por los descendientes de los Incas Emperadoes, diseminados en las ocho parroquias de la ciudad, dan poder especial y amplio al capitán Garcilaso de la Vega Inga, vecino de la ciudad de Badaoz, y a don Melchor Carlos Inga, vecino de esta ciudad, a don Fernandes de Mesa, vecino de la de Toledo y a don Alonso Marquez, per se et insolidum, para suplicar al Re y al Conseo de Indias mercedes, libertades, exenciones y privilegios que les corresponden por su calidad y descendencia real y para que no los apremien con servicios personales. Fueron testigos: El Bachiller Francisco Navarro, Cristobal de Aller y Juan Pérez Montañez; ante Miguel Mendo, 
escribano público. El traslado esta sacado por Gaspar Prado, escribano del Rey y Público, (Audiencia de Lima, 472. Archivo Histórico, Cusco, 1963).

El "hijo natural” del Capitán Sebastián Garcilaso, fue forjando su relevancia identificadora, lo que vendría a ocurrir cuando "se hace escritor", por lo demás, su linaje ya era distinguido en la letras españolas, figurando nombres de parientes suyos, como el poeta Gómez Manrique, Jorge Manrique, el inmortal autor de las

\section{"El Gran Inca Garcilaso}

de la Vega, no fue un hijo

más de la conquista, un

hombre de vida destruida,

bastardo, o hijo de

ocasión y pecado, fue

parte de los primeros

peruanos de quien

tenemos orgullo."

Coplas a la muerte del Maestre Don Rodrigo y el gran poeta del Renacimiento español, Garcilaso de la Vega.

Con el reconocimiento de los "otros", condición que valida la identidad, en aquellos "rincones de soledad y pobreza", como denomina a Montilla.

Luego de la traducción de "Los Diálogos del amor", le siguieron sus obras ya conocidas, pero con la tarea de escribir los Comentarios Reales, para "aclarar graves malos entendidos por causa de la incomprensión del quechua por parte de los cronistas españoles, por no entender el idioma que se le daba, o por no entenderse al otro, por la dificultad del lenguaje; que el español piensa que sabe más de él, ignora de diez partes las nueve, por las muchas cosas que un mismo vocablo significa, y por las diferentes pronunciaciones que una misma dicción tiene para muy diferentes significaciones por no haber referentes europeos".

Como frente a la cultura andina iba emergiendo otra de fuerte connotación occidental a partir de la imposición de su idioma y su religión entre otros elementos, que se perfilaban como dominantes, el problema se tornó en extremamente complejo a nivel de la sociedad, pues, fueron colisionando los espacios culturales, como tal, fue evidente el intrincado panorama de las identidades, entre construcción, redefinición o reajuste e inclusive los propósitos de negación.

\section{Conclusiones}

1. La primera generación de descendientes de los castellanos o, "hijos de los conquistadores", entre ellos el Inca Garcilaso de la Vega, fueron víctimas del complejo entrecruzamiento de categorías y narrativas identitarias acerca de "él", "nosotros", "nosotros mismos" y "otros".

2. En el caso de Inca Garcilaso de la Vega, a través de su nombre y de su escudo, se rastrea la invención de una nueva identidad del "Inca mestizo". Se detiene especialmente en la significación que subyace en la iconografía de ese escudo la expresión de su pensamiento y su sentimiento, cargado de una indudable intención de alegato político contra la actitud de las nuevas estructuras dominantes frente a los descendientes de los últimos soberanos incas, vivos aún y que él sería uno de sus referentes.

3. Correspondió a José de la Riva Agüero, uno de los representantes de la 
Generación del 900, retomar la atención sobre Inca Garcilaso de la Vega, y fue en 1903, a través de su "Examen de la Primera Parte de los Comentarios Reales"; así mismo en 1916, con motivo del tricentenario de la muerte del Inca Garcilaso de la Vega, José de Riva Agüero, pronunció el discurso "Elogio del Inca Garcilaso", discurso que generó severas críticas del joven periodista José Carlos Mariátegui.

4. A partir de aquel loable gesto de Riva Agüero, se continuó con la preocupación por conocer y difundir la obra garcilasiana, así, Aurelio Miró Quesada identificó el testamento que la Isabel Chimpu Occllo (1571), donde un testigo firmó por ella, poniendo el nombre de Isabel Suárez, parece que la ñusta nunca llegó, o no quiso hablar el castellano.

5. Con las obras de Garcilaso, los indígenas ganaron cierto espacio político, y contrariamente, también, con la voluntad activa del Estado colonial que necesitó de un actor étnico, lo que se visibilizó con las crónicas principalmente de Juan de Betanzos y de Cieza de León. Según Christian Gros, bajo la apariencia de reconocer la comunidad indígena, el Estado produce, reproduce y legitima una frontera étnica. No olvidemos que estas circunstancias se dieron desde muy temprano, así en 1542, cuando se promulgaron en Barcelona las Leyes Nuevas inspiradas en las apasionadas demandas de Fray Bartolomé de las Casas, aboliendo el trabajo forzado de la población indígena y limitando los privilegios de los conquistadores y encomenderos.

Evidentemente las diferencias como conjunto de repertorios culturales interiorizados: representaciones, valores y símbolos, continuarían y a través de los cuales tales actores sociales fueron demarcando sus fronteras de distinción identitaria como construcción y reconstrucción, a pesar de las imposiciones, por lo que no hubo "intercambios" sociales. Fue la grandiosidad de la cultura andina que obligó a los aventureros, entre ellos a los curas, responsables de la imposición ideológica a aprender el quechua, conocer las costumbres, etc. y así diseñar las "estrategias" de su proselitismo ideológico, incluida la extirpación de idolatrías.

\section{Sobre las contradicciones}

españoles-indios, que más allá de oposición de clase, fueron de tipo cultural, asunto que no debe concebirse como un fenómeno independiente o ajeno a la estructura de clases de la colonia y aún la república, ni las clases deben abordarse sin considerar la dimensión sociocultural, como afirma mi profesor Díaz-Polanco (1981). Este asunto nos debe llevar a entender la importancia de cómo determinados sectores de la sociedad, generan discursos y movilizando sus propiedades con efectos en la construcción de las diferencias. No es entonces única y exclusivamente la diferencia cultural, la fuente de la etnicidad y multiculturalidad, sino la comunicación cultural que permite trazar fronteras entre determinados sectores de la sociedad.

El Gran Inca Garcilaso de la Vega, no fue un hijo más de la conquista, un hombre de vida destruida, bastardo, o hijo de ocasión y pecado, fue parte de los primeros peruanos de quien tenemos orgullo.

7. Si bien terminó la vida del Inca Garcilaso de la Vega, quedaron sus obras, particularmente los Comentarios Reales, texto que fue prohibido por la represión española, luego de la revolución de 1781 de Túpac Amaru, por cuanto fueron consideradas sediciosas y peligrosa para los intereses colonialistas. Obviamente con aquella revolución, fuertemente motivada por las lecturas de las obras de Inca Garcilaso de la Vega, las comunidades indias reaparecen en la escena política reivindicando el status de pueblos y naciones. Estas recomposiciones sociales nos hablan de un proceso continuo de renovación de identidades.

Desde luego la respuesta colonial fue extrema, llegando al caso de prohibir el 
habla quechua, así ingresarían colectivamente en una crisis identitaria, la misma que habría tal vez de prolongarse hasta tiempos de la República, cuando José de San Martín luego de ritual político de la Independencia, en agosto de 1821 abrogó el tributo indígena, luego restituida en 1825 por Simón Bolívar.

Uno que otro ejemplar de la obra de Garcilaso de la Vega existía en la Universidad San Antonio Abad, hasta que nuevamente durante la revolución anticolonial de 1814 conducido por los hermanos Angulo, la requisa dispuesta por la corona hizo desaparecer.

Miguel de Unamuno ${ }^{7}$ escribió: [...] Morir soñando, sí, más si se sueña morir, la muerte es sueño; [...] vivir el día de hoy bajo la enseña del ayer deshaciéndose en mañana [...]. Poema, que tal vez nos traslade a los últimos días de Inca Garcilaso de la Vega, hombre que llevó una vida muy compleja y llena de contrariedades, de ahí, no es posible referirnos al Gran escritor, fuera de su contexto.

Tal vez escribir sobre el Gran Garcilaso Inca de la Vega, esté condicionado por diversos factores, aquí tiene su lugar la advertencia de Valcárcel: "El Cusco y Lima son, por naturaleza de las cosas, dos focos opuestos de la nacionalidad. El Cusco representa la cultura madre, la heredera de los incas milenarios. Lima es el anhelo de la adaptación a la cultura europea... ¿será capaz el espíritu europeizado, sin raigambre en la tierra maternal, de enorgullecerse de una cultura que no le alcanza?...Sólo al Cusco le está reservado redimir al indio" (Valcárcel. L.1927)

Reivindiquemos eternamente su personalidad, obra y pensamiento, esperamos que algún día la Universidad acional de San Antonio Abad del Cusco pueda instituirse en el Cusco y su ciudad, la "Cátedra Inca Garcilaso de la Vega". REFERENCIAS

Archivo General de Indias. Audiencia de México 1068. Libro 4, fol. 239v.

Archivo General de Indias. Audiencia de Panamá 233.

Libro 2, fol.45v.

Audiencia de Lima, 472. Revista del Archivo

Histórico de Cuzco, 1963.

Betanzos de, Juan. "Suma y Narración de los Incas" [1551]. Universidad Nacional de San Antonio Abad del Cusco. 385 págs. Cusco, 1990. Texto re editado bajo mi dirección como Asesor del Rectorado.

Chang-Rodríguez. Raquel. Mujer y Cultura en la colonia hispanoamericana (Pittburg: IILI, 1996)

Conetzke, Richard. Celulario de Ayala, tomo 9, fol. $14 \mathrm{v}$.

Colección de Documentos para la Historia de la Formación Social Hispanoamericana 1493-1810. CSIC, Madrid. 1953.

De la Riva Agüero, José. "Examen de la Primera Parte de los Comentarios Reales de Garcilaso Inca de la Vega". Oficina Litográfica de Opinión Nacional", Gremios 441. Lima 1903.

Díaz-Polanco, Héctor. Etnia, clase y cuestión nacional

.Cuadernos Políticos, número 30,

México, D.F., editorial Era, octubrediciembre de 1981.

Gros, Christian. Políticas de la etnicidad: Identidad, Estado y modernidad. Instituto Colombiano de Antropología e Historia. 2012.

Lisón Tolosona, Carmelo. Las máscaras de la identidad: claves antropológicas. Ariel, 1997.

Marchena Fernández, Juan. Los hijos de la Guerra: modelo para armar. Congreso de Historia del Descubrimiento (1492-1556). Actas Vol.III. Real Academia de Historia. Madrid, 1992.

Miró Quesada S. Aurelio. Prólogo de Comentarios Reales de los Incas. Librería Internacional del Perú. S.A. Lima, 1959.

Paredes Pando, Oscar. Primer Diálogo de la Justicia Intercultural. Conferencia 
"Bases para la Institucionalización del Espacio del Diálogo Intercultural". Corte Superior de Justicia del Cusco. Octubre, 08 de 2016.

Rostoworoski de Diez Canseco, María. "El repartimiento de Doña Beatriz Coya en el valle de Yucay". Revista de Historia y Cultura 4 (1970): 153-267.- Doña Francisca Pizarro. Una ilustre mestiza, 1534-1598. Lima: IEP, 1989.

Sánchez, Luis Alberto. Garcilaso Inca de la Vega. Primer

Criollo. Editorial Eusonia Talleres, Lima, 1979.

Toynbee, Arnold (1966) Prólogo at The Royal Commentaries of the Incas and the General History of Peru, Garcilaso Inca de la Vega, H.Y. Livermore (ed.), University of Texas Press, Austin.

Valcárcel, Luis E.(1927)Tempestad en los Andes. Ed.

Minerva

, Lima.

Vázquez Medel, Manuel Ángel (1998): Tendencias actuales del comparatismo literario en revista electrónica del GITT CUS http ://www.cica.es/ aliens / gittcus/02.11.2016

$/ 17.00$ horas. 